\title{
A Literature Review of Pulmonary Function Test of Wind Instrument Players
}

\author{
Rashmi Shahu* \\ Shri Ramdeobaba College of Engineering and Management, India
}

Submission: August 05, 2017; Published: August 24, 2017

*Corresponding author: Rashmi Shahu, Shri Ramdeobaba College of Engineering and Management, India, Email: rashmishahu17@gmail.com

\begin{abstract}
It is well known that a lot of respiratory function is used by Wind Instrument players to produce sound. Often, for improving lung functions, continuous respiratory training is suggested which can be achieved by playing wind instruments. So, wind instrument players tend to have higher lung functions. But this does not mean that these players are not prone to any kind of lung diseases. People still have contradictory results on the studies related to this issue. This paper reviews various literatures related to pulmonary functions, wind instrument players and spirometry test.
\end{abstract}

Keywords: Pulmonary function; Spirometry; Wind instrument players; Respiratory functions

\section{Introduction}

As they say "Music soothes the soul and heals the heart". On the contrary, one who perceives music is much healthier than the one who creates music playing instruments. This study is related to the effect of playing wind instruments on the pulmonary functions. A Wind Instrument is a musical instrument which produces sound by a vibrating column of air. When the player blows through the mouthpiece it vibrates the air which then creates tone of music. Wind instruments are classified into two: woodwind and brass winds. (musiced.about.com) Brass creates sound through the vibration of player"s lips on the mouthpiece. Woodwind instruments produce tone by adjusting length of the vibrating column of air. Clarinet is one example of woodwind family and is played by blowing wind directly into the instrument"s edge. (Music Education about.com clarinet) Bagpipe is another instrument that belongs to wind family. The key lies in the lung-power responsible for playing the bagpipes. (Music Education about.com bagpipes) The techniques involved in playing the wind musical instruments are the breathing technique and the fingering technique to control the pitch of the tone. Many claims in the past regarding the respiratory infection caused by playing wind instruments have been reported. On May 23, 2011, the New York Times published the study that claims the risk of infection caused by wind instruments. In a study, the scientist tested 20 instruments -flutes, clarinets, trumpets and saxophones. The study revealed that all instruments were found to harbor living bacteria, mold and yeast, some of which survived for several days when cultured. Shortness of breath and coughing is termed as 'hypersensitivity pneumonitis' that happens to brass musicians who may unknowingly inhale mold and bacteria from their instruments. (23 May, 2011 New York Times, Anahad O"Connor Respiratory Claim) Interestingly, a saxophone player from Medford was not surprised that scientists have got a link between brass wind instruments and lung disease. American scientists at University of Texas health Science Center documented the case of a 35 year old with trombones player"s lung. He had a non-productive cough for 15 years with no other medical explanation. For every problem, there is a solution. When American researchers examined the study subject's trombone, they found large number of micro bacteria. After immersing his instrument in 91 percent isopropyl alcohol, the trombone player saw his cough disappear and he has been symptom free for 20 months. Experts say that musicians should routinely clean wind instruments with soap and water or alcohol wipes. (7 September 2010 abcnews Medford saxophone player) John Robert Brown, a musician and a writer, says that playing wind instrument definitely interferes with normal breathing but it is misleading the fact that it is not the force but the control of breathe that matters. (John Robert Brown Breathing) This paper reviews the existing literatures and research works related to pulmonary functions, use of spirometery for pulmonary function tests, determination of sample size, respiratory functions.

Review of Studies Regarding Pulmonary Function and Spirometry

Mohan Sagdeo et al. [1] conducted an experiment on a group of wind instrument blowers who were healthy and non 
smokers and a group of non blowers by using wind instruments to test the pulmonary and physiological effects on human body. Medispiror was used to test the pulmonary changes taking place in human body. Data was recorded for various parameters such as Forced vital capacity, Forced expiratory volume, Peak Expiratory flow rate etc following which maximum voluntary respiration rates were recorded for three sets of reading and the same were analyzed by using ANOVA. The conclusion that was drawn out from these studies and sets of experiments where in similar profession like glass blowing was also considered apart from vast range of wind instrument blowers is that the trained wind instrument blowers have better pulmonary functions as compared to non blowers which is an outcome of regular training of blowing wherein ventilator muscles are under constant exercise and are well trained which might be of physiological advantage as these strengthen the ventilator muscles. The external factors which might be an affecting factors include the amount of training and motivation each blower is provided with and this could lead to variable pulmonary functioning of human body. Sunita Dhule et al. [2] conducted a study with an objective to identify the lung functions and related physiological changes in human body that are affected by pulmonary activities of body. The study considered a sample size of 30 wind blowers where in Forced Expiratory Manoeuvre and Maximum Ventilation Volume Manoeuvre was analyzed. It was concluded that the pulmonary functions are more developed in the trained blowers as their ventilatory muscles are well trained for prolonged expirations and proper breath control which results in improved abdominal muscular and diaphragmatic functions in the body. This can be considered of great physiological aid in treatment of serious respiratory diseases and sleep related diseases.

Khuje et al. [3] performed a comparative study on a group of clarinet and trumpet players who fall in the age group of 20 25 years. Pulmonary functions were tested and recorded using a HELIOS 401 RMS medspiror. During the study, lung functions were tested and recorded and were further analyzed by using statistical tools and graph pad prism 5 software. The conclusions drawn from this study indicate that better trained the ventilator muscles, better is the pulmonary functioning in the body, kind of instrument, motivation, training influence the pulmonary functions of the body. Also, the results show that the clarinet players had higher pulmonary functions than the trumpeters.

Fuhrmann et al. [4] aimed to find the impacts on respiratory functions of the wind instrument players. This study was performed on a group of musicians and non musicians between the age group of 18 and 60 yrs who were subjected to playing wind or brass instruments. And were non smokers and their respiratory conditions were considered to be fit before the study. Author has employed various techniques like forced oscillation tests, static lung volumes, Gas transfer, histamine challenges, etc. There was no evidence in this study that maximum pressure „profiles" of W/B instruments are associated with differences in lung function. It is evident through the study that the choice to play a W/B instrument is not likely to be impacted by one"s lung flows or volumes. Neither is there any consistent evidence that the physical practice of playing a W/B instrument alters flows or volumes. Infact, a very useful conclusion is drawn that the ability to sustain long musical phrases with expression is a result of having learned to control airflow, not necessarily due to having better lung functions. Devadiga et al. [5] investigates on two groups of people, where in one group of instrumentalists was assigned wind instruments such as flute saxophone and nadswaram, whereas the second group comprised of non instrument players. The Author analyzed Vital Capacity, peak flow and phonation quotient for the two groups whose age group was between 18-40 years. Aerophones were used to assess the aero dynamic measures. As a result, the strength of expiratory muscles was found to be on a higher side in the wind instrument players. The conclusion drawn by the author can be used as a useful reference which says that the amount of air potentially available for phonation is not a pre requisite for being a better instrument player.

Zuskin E et al. [6] explains the effect of playing wind instruments on lung function and respiratory symptoms. The author included 99 wind instrument players and a group of 41 string instrument players. Data on chronic respiratory symptoms was collected. And lung function was measured. It is found that the musicians playing wind instruments with who use their instruments for longer time span had higher lung function. This study data suggests that wind instrument players have a higher tendency of chronic upper airway symptoms. Deniz et al. [7] conducted a study by comparing 34 male, non-smoker wind players in a military band with 44 healthy nonsmoker males by pulmonary function testing. The study shows that wind players have lesser spirometric values. The author has also concluded that class of wind instrument, brass or wood, showed no significant differences. The data from this literature refers that it may be the development of asthma or constant barotrauma during their playing which affects the pulmonary function in musicians playing wind instruments. Feyrouz Al-Ashkar et al. [8] conducted a descriptive study for interpreting pulmonary function tests. The study reveals that pattern of abnormality should be first understood. Patients" history should be well considered to find the causes of abnormalities. The author has clearly mentioned the indications for PFTs which might be very useful in related studies. A systematic approach given here, includes firstly, to confirm the patient"s demographic data. Secondly, to test for acceptability and reproducibility. The final step would be to interpret the results by determining if the pattern is obstructive, restrictive, or normal and then to find the severity of the defect. Harpreet et al. [9] has conducted a study on Pulmonary Function Tests. This study shows the importance of PFTs for the treatment of patients suffering from the respiratory disease. Normal values and flow volume curves in combination with the patient"s clinical history helps in interpretation of 
patient"s health. The knowledge of respiratory physiology is a must for interpretation of these tests. The paper can be used as the basis for general considerations and normal values. Timothy J. Barreiro et al. [10] has developed simple systematic method for interpreting spirometry. Changes with time have brought vivid advancements in technology which has undoubtedly made spirometer much more useful and thrust worthy along with ease of use. The authors" method includes firstly validation of the test. Second comes the determination of the pattern followed by severity if a ventilator pattern is seen. Robert et al. [11] mentions the affect of asthma on the Australian population. The methodology followed was by providing the music lessons to all the children of Aboriginal Medical Service and a community centre by allotting the male children didgeridoo and females singing and clap sticks. Didgeridoo is an aboriginal wind instrument. At regular intervals spirometry was performed and their comments were recorded. The author has done a proper data analysis for the comparison of the respiratory data. Results of the study benefited the health of the students and small improvements were discovered. This technique can be used not only for improved respiratory functions but also to increase awareness for asthma management. Don et al. [12] through his cross sectional study, provided enjoyment and improved health conditions. He had started the study with the main objective of engaging the victims of asthma in music lessons to support management of their asthma. The participants of the study included both males and females. A didgeridoo made by an Aboriginal craftsman was given to male candidates and $\mathrm{mp} 3$ player containing backing tracks and voice exercises were given to females. Spirometry was used to determine the respiratory functions and along with it questionnaires were completed. Analysis was done using paired t-tests. Author fulfilled his purpose of study by getting results which included recruitment and retention, better quality of life and by proving that music has a great potential for improved respiratory functions and asthma management. Suvi Hänninens [13] study is related to the music therapy for Asthma and Chronic Obstructive Pulmonary Disease (COPD) rehabilitation. The research work done by the author is mainly to suggest if breathing Woodwinds can be an useful music therapy as a treatment. Breathing exercises and playing wind instruments was used as a method for strengthening respiration. The patients, after the music session were more open to this idea and the results indicated that the music provided support for treating pulmonary patients. Author has found strategies to optimize wind instruments affect to strengthen patients control over respiration. David [14] preliminary report refers to the subjects for study as four skilled musicians and one rank novice where all were brass instrument players. The pneumotachograph was the equipment used to determine the thoracic, abdominal, and lung volume changes during playing. The study suggests that the rib cage and the abdomen contribute to the expiration. Also, the inspiratory lung volumes and repetitive passage does show a relationship with performance skill.

\section{Review of Sample Size Studies}

James et al. [15] explains that any study design that aims at establishing certain facts has an integral part of survey or research which can be carried out on a group or data available. Further, the author convinces that one of the important aspects of survey or sampling is determining the sample size that needs to be taken into consideration. This study gives an important note that determination of sample size must be done while taking into consideration various factors like the parameters or variables that are being studied need to be carefully and clearly defined and the same should be then incorporated into the calculation methodology that is to be adopted to arrive at the final conclusion of the research sampling. According to this paper, the other parameters that can prove helpful in determining sample size is the specification of error limit or the tolerance range in which error variance is acceptable, also one needs to take into account the variances that crop up during the study, as certain factors are beyond the control of the researcher and may vary from the estimated limits or figures. The other aspects that need to be known to the researcher for setting up the sample size and proceeding with sample size calculation includes determination of continuous data which takes into account if the data is categorical or continuous and accordingly the formulae should be used. Other sample size determination considerations comprise of regression analysis method which is used when the mentioned rules cannot fulfill the sampling purpose. Thus, the conclusion that can be drawn from this study is that these methods are an added guideline for the researcher and the study must be planned by taking into considerations all factors that affect the initial or final results of the survey. The formula which the author has provided in this study can be used for calculation of sample size for survey research. Jeff Watson [16] in his study of "How to determine a Sample Size" explains that for surveying a large group of people or analyzing a large set of data, a sample size needs to be determined which can be established by considering the following factors. Firstly the final output or the goal that is to be achieved must be clear and accordingly the sample size must be drawn from the available population by considering the needs of the goal that has been set and the available tools and resources which could affect the sampling study. Secondly, how precise the results obtained is a fact that surveyor needs to identify. The closeness of values obtained to actual values should be specified and justifiable and accordingly sample should be drawn. Third aspect which the author mentions is the determination of confidence level which indicates that the sample size is well within the acceptance range. Lastly the response rate for any survey must be analyzed as the final number of respondents should satisfy the study criteria and accordingly the sample size should be drawn. This literature is referred as basis for consideration is the variability factor. Shuo Li et al. $[17,18]$ calculates the standard deviation for the population by taking the sample readings from the field. The author aims to establish a consistent method for collection of data 
and investigate the various factors which might affect a study. A modified equation is presented to estimate the minimum sample sizes for field data collection. It is advised to use the standard deviation to measure the data dispersion of the collected data when the sample size requirements are to be estimated.

\section{Conclusion}

The literature review shows conflicting result on effect on Pulmonary function on wind instrument players. The paper suggests that more studies with larger sample size should be conducted for getting accurate results.

\section{References}

1. Mohan M, Prashant D (2012) Pulmonary functions in trained and untrained wind instrument blowers. Peoples Journal of Scientific Research 5(2): 9-12.

2. Sunita S, Bisht, Swati R (2008) Pulmonary function tests in wind instrument players. International Journal of Science and Research (IJSR) 2(5): 384-386.

3. Khuje PD, Sandip MH (2012) Comparative study of pulmonary functions of clarinet and trumpet players. research journal of pharmaceutical. Biological and Chemical Sciences (2): 746-751.

4. Fuhrmann AG, Franklin PJ, Hall GL (2011) Prolonged use of wind and brass instruments does not alter lung functions in musicians. Respiratory Medicine 105: 761-767.

5. Deepa N, Jayashree S, Bhat V (2014) Aerodynamic measures in wind instrument players. Paripex - Indian Journal of Research 3(12): 95-97.

6. Zuskin E, Mustajbegovic J, Schachter EN, Kern J, Vitale K, et al. (2009) Respiratory function in wind instrument players", La Medicina del Lavoro. Med Lav 100(2): 133-141.

7. Deniz O, Savci S, Tozkoparan E, Ince DI, Ucar M, et al. (2006) Reduced pulmonary function in wind instrument players. Archives of medical research 37(4): 506-510.
8. Feyrouz A, Reena M, Peter J (2003) Interpreting pulmonary function tests: Recognize the pattern, and the diagnosis will follow. Cleveland Clinic Journal of Medicine 7(10): 866-881.

9. Harpreet R, Michael W, Brendan M (2011) Pulmonary Function Tests. The Ulster Medical Society, pp. 84-90.

10. Timothy J, Irene P (2004) An Approach to Interpreting Spirometry. American Family Physician 69(5): 1107-1114.

11. Eley R, Gorman D, Gately J (2010) Didgeridoos, songs and boomerangs for asthma management, Health Promotion Journal of Australia 21(1): $39-44$.

12. Robert E, Don G (2010) Didgeridoo playing and singing to support asthma management in Aboriginal Australians, Short title: Music therapy for asthma. Centre for Rural and Remote Area Health 26(1): 100-104.

13. Suvi H (2014) Breathing woodwinds-music therapy for asthma and copd rehabilitation. Master"s Thesis, Music Therapy Department of Music, University of Jyväskylä, p. 41.

14. Cugell DW (1986) Interaction of chest wall and abdominal muscles in wind instrument players (A preliminary report), Cleveland Clinic Quarterly 53(1): 15-20.

15. James E, Joe W, Chadwickk C (2001) Organizational Research: Determining Appropriate Sample size in Survey Research. Information Technology, Learning, and Performance Journal 19(1): 43-50.

16. Jeff W. How to Determine a Sample Size": Tipsheet \#60, University Park, PA: Penn State Cooperative Extension.

17. Shuo L, Karen Z, Van G, John N, Carl T (2002) Reconsideration of sample size requirements for field traffic data collection using gps devices. TRB 2002 Annual Meeting, Paper 1804: 1-18.

18. Bouhuys (1964) Lung volumes and breathing patterns in wind instrument players. J Appl Physiol 19: 967-975.

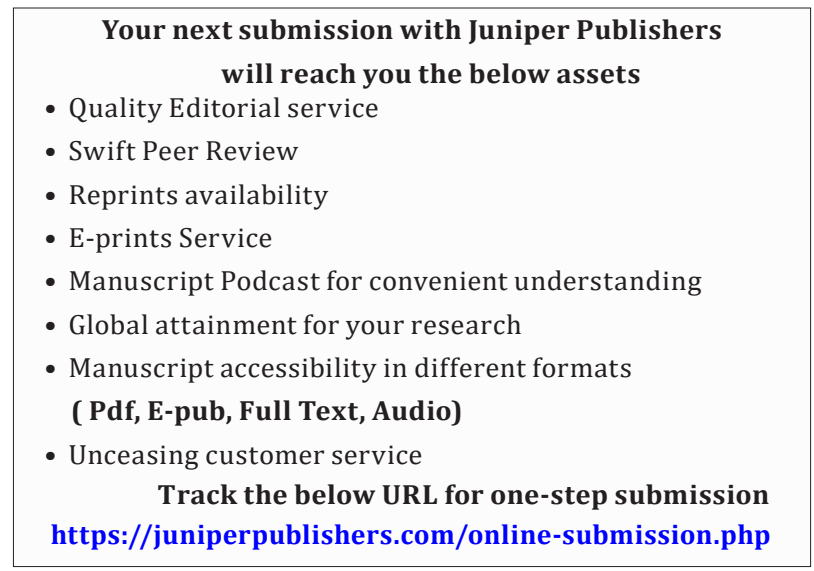

